\title{
Chapter 9: Art in Second World War Museums
}

The last chapter of this study deals with the use of art in historical Second World War exhibitions in today's museums. Analyzing history museums' use of art provides the perfect lens for understanding how museums can restrict or produce experientiality for their visitors. Artworks - such as sculptures, paintings, or drawings - are functionalized as additional historical sources. As such, they can provide introspective opportunities for understanding primary experiences and can allow for critical and reflexive thinking. Art is present in the form of paintings and sculptures, and more indirectly in the architecture and scenography of interior museum spaces in all of the museums analyzed. However, only a few museums trust artwork as an autonomous medium that allows the visitor to form aesthetic judgments outside the narrative, ideological, or historical framework provided by the museum. The aesthetic potential of art can be explained using Immanuel Kant's theory of the four possible aesthetic reflective judgments: the agreeable, the beautiful, the sublime, and the good. The two subjective universal judgments of the beautiful and the sublime, which Kant developed in his Critique of Judgement (Kritik der Urteilskraft), help us understand how the visitor can use artworks for further reflection, contemplation, and critical interpretation of history, without either falling into merely subjective statements or being bound to a predestined ethical imperative. Kant notes:

The beautiful coincides with the sublime in that both please for themselves. And further in that both presuppose neither a judgment of sense nor a logically determining judgment, but a judgment of reflection: consequently the satisfaction does not depend on a sensation, like that in the agreeable, nor on a determinate concept, like the satisfaction in the good; but it is nevertheless still related to concepts, although it is indeterminate which, hence the satisfaction is connected to the mere presentation or to the faculty for that, through which the faculty of presentation or the imagination is considered, in the case of a given intuition, to be in accord with the faculty of concepts of the understanding or of reason, as promoting the latter (Kant 2000 [1790], 128). ${ }^{1}$

Obviously, historical events in war go beyond Kant's concept of the beautiful and sublime. Knowledge presented in a museum will never reach the autonomous and self-referential status that a piece of artwork that pleases or overwhelms the recipient aesthetically can achieve. Nevertheless, Kant's tracing of a concept

15 : 244. Beginning of $\S 23$. "Transition from the faculty for judging the beautiful to that for judging the sublime."

๑ OpenAccess. ๑ 2020 Stephan Jaeger, published by De Gruyter. (cc) BY-NC-ND This work is licensed under the Creative Commons Attribution-NonCommercial-NoDerivatives 4.0 License. 
of reflection that brings together the indeterminate of imagination and the understanding of reason helps us reflect upon how artwork in history museums contributes to the development of experientiality by creating spaces for the visitor's perception, contemplation, and interpretation. ${ }^{2}$

There are also drawings and paintings of the Holocaust in almost every war and Holocaust memorial museum. The victim-authored, mimetic language in a history museum still offers some of art's resistance, or in Theodor W. Adorno's words from Aesthetic Theory (Ästhetische Theorie), some of the tension and gaps between the empirical thing and the spirit of the artwork (Adorno 1997 [1970], 277). These allow art to be an adequate language for the unspeakable experience of extreme violence in history. Unlike Kant's focus on the perception of the subject, Adorno locates art's truth content in the internal dynamics of the art object and in its socio-historical context. He emphasizes that all artworks are enigmas that express "the duality of being determinate and indeterminate" (Adorno 1997 [1970], 124) and sees the dialectical process of artwork between their experience and their "enigmaticalness" (Adorno 1997 [1970], 125). Consequently, works of art resist their mimetic explanation; they cannot be fully utilized for an illustrative purpose or as part of a closed narrative structure.

A historical museum normally uses artwork for a pragmatic purpose, reducing its aesthetic truth content by treating art as a merely cognitive argument, ignoring its enigmaticalness. Most visitors are probably less likely to engage in the autonomous or self-referential quality of artwork if it fulfills either a narrative or illustrative function. However, if a war or history museum uses autonomous artwork, it invites or challenges the visitor to explore its inherent meanings and ambiguities. These works are connected to the exhibition space around them; they might be marked through a primary symbolic interpretation provided by the museum or the artist. However, they also draw the visitor into a one-on-one communication with the artwork. Since the violence of war, atrocities, and suffering offers plenty of challenges to which there is hardly one answer, artwork relating to war, violence - and the Second War in particular - offer the visitor the potential to interact with the past, which is even more relevant with the looming end of living memory that requires the activation of the visitor's imaginative perception capabilities.

Most exhibitions analyzed - with the exception of the Bundeswehr Military History Museum, the Imperial War Museum North, and the House of European

2 For the role of Kant's aesthetics in the development of the exhibition concept for the Bundeswehr Military History Museum and an artifact's potential for unearthing multiple layers of history in the process of reception see also Müller 2006, 758. 
History - do not use autonomous artwork. One only occasionally finds paintings and portraits illustrating a theme or depicting a person in a typical wartime scenario. In these cases, war paintings supplement other visual media, particularly photography, posters, and film. The Canadian War Museum (CWM) - in addition to the Imperial War Museum as the institution with the largest collection of war paintings - serves as an excellent example of how war paintings can supplement a museum exhibition about the Second World War through the use of painting as a mimetic medium to mediate experiences of the past (see also Thiemeyer 2010a, 283-290). The museum presents its art collection as a witness that will endure after the end of (human) living memory: "As it does, the Canadian War Museum's war art collections of 13,000 works increasingly provide a link to the conflicts from the perspective of those who witnessed them. While, to a certain extent, the paintings act as illustration, they also convey the feelings of the participants in the conflicts. This, perhaps, is their most important legacy" (Brandon 2019). The Canadian War Records of the Second World War (1939-45) contains over 5,000 small paintings. "There are no huge memorial compositions focusing on destruction, tragedy, and misery. Instead, the somewhat depersonalized emphasis [...] is on the locations, events, machinery, and personnel of Canada's war on all fronts" (Brandon 2019).

In a history exhibition, paintings are usually integrated into the overall narratives and typically illustrate or supplement a theme. For example, in the section about the Battle of the Atlantic, the CWM exhibits the painting Corvette Bridge. The description first explains that corvettes were unsuited to the rough conditions of the Atlantic. It then provides an interpretation: "This painting by Donald MacKay captures the discomfort of command on an open bridge in bad weather." Therefore, the painting and the postures and emotions of the three men on the bridge offer no further questions to the visitor. They confirm and intensify the argument about how the war was experienced by the Canadian soldier. In the D-Day / Normandy section, the visitor encounters Eric Altwinckle's painting Invasion Pattern Normandy, which "depicts a Canadian Mustang in action." The description highlights the invasion stripes that made the aircraft recognizable to other Allied aircraft. The painting shows the aircraft itself from above, its bombs, some landing crafts, and a beach beneath it. Again, war art here is merely illustrative.

If and when interpretation is needed, the CWM provides one explicit interpretation. This can be seen in the next section, where the visitor comes across Orville Fisher's painting entitled Scheldt Crossing, depicting the campaign in the Netherlands. According to the CWM, the painting "captures the dismal weather that dogged Canadians during the campaign." On the one hand, this supports the general narrative of Canadian valor and hardship. On the other, 
the painting itself is ambiguous; the Canadian soldiers are barely visible at the top of the transport vehicle. The painting could just as easily be read as a metaphor for man and machine, wherein the former becomes the latter. However, because the museum treats all artworks as historical sources that supplement arguments, such an openness of interpretation is not encouraged. Art is supplementary and maintains a documentary function, as opposed to a self-referential one. ${ }^{3}$

The more playful arrangement found in the chronology gallery in the Bundeswehr Military History Museum (MHM) serves as an exception to paintings that function as illustration of a story, theme, or argument. Here the museum creates a meta-representational display that reflects upon the evolution and function of war and battle painting as an artistic genre. It uses two large walls in its “1300-1914” and "1914-1945" galleries, respectively, to depict the artwork of the time. ${ }^{4}$ The section on Second World War battle paintings is entitled "The End of Battle Painting? The Two World Wars in German Painting until 1945-46." The paragraph about the Second World War reflects upon Nazi Cultural Policy, war painting in propagandas companies, and the persecution of 'degenerate' art. The MHM also mentions the decline of the medium in comparison to photography and cinema in the age of the world wars. Ten paintings on the wall were painted during the Second World War. They include: propaganda portraits; pictures depicting technological strength, such as a charging U-boat or an advancing tank; and images of the German army supporting local refugees from the Red Army, destroyed Soviet tanks, and Soviet prisoners of war. Whereas the MHM contextualizes most images - i.e. paintings are used to illustrate certain arguments - their setting invites the visitor to ask further questions. For example, the 1944 painting Vor dem Angriff (Before the Attack) by Werner Höll depicts three soldiers moving forward with stern facial expressions: the leader looks on determinedly with a machine gun in hand. The description provides context concerning Höll's career as a painter in the style of new objectivity (Neue Sachlichkeit) before becoming a Nazi propaganda painter. It also states that Höll resumed abstract painting after 1945. Placing the artwork in its historical context allows

3 At times, museums like the Canadian War Museum and the Imperial War Museum in London in particular, hold war art exhibitions as such. Here, the visitor has the potential to understand the range and expressional possibilities of the medium, which can develop a certain autonomy beyond the museum's explanations and display structures.

4 The MHM uses paintings as historical sources throughout the chronological exhibition as well. As seen, for example, in the analysis of the "Politics and the Use of Force" section above (see chapter 5.1), the spatial arrangement often allows the artwork to surpass a merely illustrative function. 
for open questions. The viewer can wonder whether the stern faces of the soldiers only express support for the war, think about the careers of various artists in the National Socialist era, and what choices they were faced with. Again, the MHM's networking technique can intensify the experientiality of the visit if the visitor connects this section to the near-by sections "Resistance in the Arts" or "Politics and the Use of Force." ${ }^{5}$ Of course, if one compares the curation of war art from the Second World War in Britain, Canada, and Germany, it is evident that the German perpetrator perspective requires a more contextualized and reflexive approach.

Aside from the use of war art, the visitor can most often find artwork in historical museums that want to either express trauma or mediate authenticity through witnessing. Museums present numerous sketches and paintings as personal expressions of suffering. ${ }^{6}$ These paintings can be created during wartime (as direct expressions of experience) or after the fact, as seen in the sketch series of life in Ravensbrück concentration camp by Violette Rougier Lecoq, displayed in the Imperial War Museum North (IWMN). Similarly, the IWMN shows five facsimiles of linocut prints by Helmuth Weissenborn from 1941, depicting post-war bomb sites across London, such as Holland Park, Oxford Street, and a suburban church. Weissenborn was a German veteran of the First World War, who - as a Social Democrat married to a Jewish woman - escaped Nazi Germany in 1939. Whereas these prints have a clear documentary function of illustrating the effects of the Blitz, the separate hanging of the paintings allows visitors to reflect upon their own perception: on what the paintings express, how authentic or beautified they are, and if and how they can empathize with Weissenborn's gaze. Considering his personal background, what might he have thought while capturing the destruction caused by Germans? On the opposite side of a narrow aisle, between two interior walls of voids, the IWMN displays the 1940 oil painting A House Collapsing on Two Firemen by Leonard Henry Rosoman. This painting functions in a similar way: on the one hand, the image is documentary, and on the other, the visitor is challenged to re-imagine the scene, whether as the firemen on which the house is collapsing and who will in all likelihood die, or more likely as an observer of the gruesome scene. The painting's documentary function is secondary to its emotional function.

As seen in the above analysis of Holocaust and genocide artwork in the House of European History, museums have the choice between on the one hand, integrating art into a pragmatic narrative - as partially seen in the case

5 See chapter 5.1 .

6 See also chapters 7 and 8. 
of Ritula Fränkel's and Nicholas Morris's Jozef's Coat and even more so in Yuri Leiderman Khatyn/Katyńs artwork. ${ }^{7}$ On the other hand, as demonstrated above, Chava Rosenzweig's installation A Star Shall Stride from Jacob and a Sceptre Bearer Shall Rise in the Imperial War Museum North functions as an artwork that challenges the visitor to explore a personal connection to the Holocaust without fulfilling illustrative, pragmatic, or documentary functions. ${ }^{8}$ Similarly, the Nussbaum painting in the Bundeswehr Military History Museum ${ }^{9}$ supersedes a documentary purpose, partially as autonomous artwork, partially because of the constellations with other artifacts that it opens up within the museum space.

As Rosenzweig's artwork demonstrates, autonomous art in historical museum exhibitions explicitly challenges observers to situate themselves to interact with it. Similarly, visitors can reflect upon their own position in Ingo Günther's art installation The Hiroshima Thank-You Instrument found in the "Protection and Destruction" section of the Bundeswehr Military History Museum's thematic tour (MHM). A strobe light illuminates a darkened space at regular intervals. The visitor's silhouette, whether accidentally captured or deliberately posed, is temporarily frozen on a wall covered with phosphorescent paint until erased by the next flash. ${ }^{10}$ Arnold-de Simine argues that the installation is based on constant repetition and resembles trauma rather than memory in its reenactment and repetition of horrific events. However, she also recognizes that the art installation inspires "playful encounters rather than sober reflection" $(2013,73)$. In other words, the visitor might be more interested in the original shadow effects than connecting them to the traumatic nature of the event. As the audio guide explains, art and the violence of the nuclear bomb separate human beings from their shadows, allowing visitors to question their own position when their shadow is forcibly and violently separated from their person. ${ }^{11}$

7 See chapter 6.3.

8 See chapter 5.2.

9 See chapter 5.1.

10 Günther originally created The Hiroshima Thank-You Instrument for the Hiroshima City Museum of Contemporary Art in 1995. It was adjusted for the space in the Libeskind wedge in 2011. 11 This chapter primarily highlights art installations that refer to the Second World War. Museums, such as the MHM, that are interested in violence as a structural phenomenon often exhibit commissioned artworks that have a more symbolic character that does not refer to specific conflicts. For example, upon entering the wedge on the ground floor, the visitor encounters the installation Love and Hate by Charles Sandison from 2005. The words 'love' and 'hate,' relating to anthropological feelings, are repeated thousands of times on the walls of the wedge. They seem to be in a never-ending fight, generating each other. Neither concept can disappear completely. The audio guide explains that visitors are supposed to become part of the installation with their feelings - love and hate - toward war and violence. Whether this succeeds is unclear; the art- 
The most ambiguous artwork in the MHM, which (partially) reflects upon the Second World War, is Klaus vom Bruch's video installation Capriccio, which was specifically commissioned for the MHM's "Protection and Destruction" section of the thematic tour in 2011. ${ }^{12}$ As the title indicates, it is a fantastic game, free of rules, that blurs time and space. The film is centered on a dragoon vase from China from before 1717 that was given - among other pieces of porcelain - to the Polish Electorate and King Augustus II by the Prussian King Frederick William I in exchange for 600 spare (enslaved) cavalryman. Two men wearing uniforms from Baroque Dresden perform scenes around a curtain, which - according to the museum audio guide - are intertextually reminiscent of paintings such as Raphael's Sistine Madonna and Johannes Vermeer's Girl Reading a Letter at an Open Window, both acquired by August III for Dresden in the mid-eighteenth century. ${ }^{13}$ At times, they carry the vase, inspect it, or put the lid on it; at times, the vase explodes in the fore- or background. The second layer of the film is footage from the Allied preparation of the Dresden bombing in February 1945. The vase - a symbol of Baroque Dresden - becomes the target and is destroyed multiple times. An analysis of the film's opening reveals the dynamics of artwork in relation to interpretations of the Second World War. First, the viewer sees four Mustang aircrafts emerging from the curtain, presumably flying to Dresden. The two soldiers - one riding on the other, possibly indicating a power relationship - then enter the scene and draw the curtain over the Mustangs. The next shot depicts both soldiers in a reflective pose sitting and lying on the ground; one is playing with the open dragoon vase. In the background, a damaged Red-Cross flag and a destroyed castle are shown, before a brief shot of knights riding horses and carrying swastika flags is shown. Then the curtain is completely drawn, before the soldiers open it to reveal an airfield. In the following scenes, the destruction (and reconstruction) of the dragoon vase becomes the pre-dominant theme of the installation.

What does the artwork tell the visitor about the destruction of Dresden? Violence clearly preceded the bombing, as indicated by the swastika knights and the selling of enslaved soldiers to obtain the vase. Was Dresden a legitimate target? The Red-Cross symbol could be a strong argument against the bombing, but

work is also a typical example of art with a strong symbolic message that forecloses further interpretation in similar ways to the illustrative and functionalized art discussed above.

12 Vom Bruch served as art curator for the permanent exhibition for artwork, both his own and that of six other artists, which were specifically commissioned for the thematic tour in the Libeskind wedge (Altmann 2012).

13 For the visitor to find such intertextual links, it is presumably crucial to listen to the audio guide. 
also a cover-up of Dresden's military past. The whole set-up feels very much staged, alluding to the illusions of theater. The soldiers and the knights seem to reenact older scenes, so that the viewer is consistently challenged to differentiate between theatrical play and historical reality. This is enhanced through the metaphor of the curtain. Is it possible to simply open and close the past? To see the destruction of Dresden's beauty? The film playfully ironizes such gestures, while displaying the interwoven dynamic between high culture and violence. While this symbolic meaning is evident, the viewer must decide what play they want to see. What violence can be justified and in which circumstances? The fact that the museum exhibits a dragoon vase, acquired on loan from the Porzellansammlung by the Staatliche Kunstsammlungen, in its " 1300 -1914" chronological section supplements the effect of vom Bruch's installation in challenging the visitor to reflect on the vase's presence in a military history museum.

The curtain also alludes to Libeskind's wedge. Whereas from the tip of the wedge on the top floor, the visitor can see an obstructed view of Dresden's reconstructed cityscape as if looking through a semi-open blind, in vom Bruch's artwork, the curtain can be fully opened or closed. The viewer is eventually confronted, however, with a similar ambiguity regarding how to connect Baroque Dresden and the Dresden of the Second World War and how to connect culture and war. The visitor has the best view of the artwork from the staircases of the old arsenal building, and Capriccio therefore also reflects the tension between the old Arsenal building - erected in the 1870s and used as museum during the Third Reich and the GDR - and Libeskind's deconstructing wedge. Increasingly, the relationship between violence and Dresden's past, between victimhood and perpetration, and between its cultural heritage and destruction allows for secondary experientiality that connects the artwork with the museum's architecture, the permanent exhibition, and Dresden's cityscape. ${ }^{14}$

14 Other self-reflexive commissioned artworks include several installations that anchor the third level "Memory" in the wedge. Nancy Davenport's Der Koyote (The Coyote) shows an awkward male protagonist on the construction site of the museum experimenting with explosives and weapons. He consistently fails in his violent ambitions, and the violence turns against him - without any indication that he learns from his failures - creating humorous incidents in the tradition of the American cartoon series Coyote and Roadrunner. What one should do with this artwork is left completely open. Is it a critique of all forms of violence? A meta-commentary on the need of the MHM to be a dynamic institution in order to prosper? Does it force visitors to reflect upon their own enjoyment of violence in the comic tradition? Or is it just entertainment? How do visitors accept that artwork in a military history museum can tell them something about violence and make them think about their own attitude toward violence and its consumption. 
Regarding the idea of deconstructing the monumentality of war as well as the unquestioned affirmative monumentality of Dresden's cultural past, one of arts' effects manifests where the commissioned artworks, Libeskind's architecture, and the spatial patterns of the exhibition meet. As seen in the air-war chapter above, the deconstruction of the V2's aura relies on the cooperation between the art installation of Klaus vom Bruch's und Manuela Günther' Galileo's Monologue, Libeskind's voids, the interior design, and curated spatial connotations between objects. ${ }^{15}$ The effect of the artwork - sometimes stronger, sometimes less intense - is a constant interaction between play, symbolic meanings, gaps, and ambiguities. ${ }^{16}$ These works of art - similar to the Imperial War Museum North and the House of European History ${ }^{17}$ - mainly offer a playful, multifaceted, or symbolic reflection; whether or how to interact with the artwork, re-

Similarly, Martha Colburn's film installation Triumph of the Wild I\&II (2008) forces visitors to situate their own perception in confrontation with the artwork. On the one hand, there is a clear symbolic message that is explained in the audio guide: humans become animals, hunters become the hunted, and vice versa. In flashbacks, the film attempts to simulate the post-traumatic stress disorder of American soldiers who fought in the Iraq and Afghanistan wars. On the other hand, viewers must decide whether they invest emotionally in the images to become - to a certain extent - part of this experience. At the same time, the visitor is challenged to connect the artwork to other forms of expressions of trauma in the permanent exhibition to make sense of an encounter with artwork in this space.

15 See chapter 8.

16 Another artwork that the visitor cannot decipher in its historical context, but relates the Libeskind building with the visitor experience of war and violence, can be found in the section "The Formation of the Body." The sound installation Mass Block by Carsten Nicolai was also specifically commissioned for one of the museum's voids. The visitor experiences "[a] collage of original sounds from theaters of war and propaganda" that "forms the acoustic sphere that associates with modern music.” The sounds and vibrations become a physical experience for the visitor entering a kind of tunnel on a grid, which reveals a deep void underneath. This can raise questions about one's own position in regard to the sounds and formations of war. It seems like an abstract form of empathy, in which the visitor can connect to the possibility or impossibility of feeling violence and war in a museum. One possible historical contextualization is given by the diorama installation, by Jens Najewitz and Maik Rohde, of people, animals, and vehicles that were part of a military division in the First World War. The viewer can feel as if they have become part of the 13th Bavarian Infantry Division in February 1918, which was comprised of about 13,000 people, 3,000 horses and 26 field artillery guns. The last sentence of the description notes that every two days, 16,000 soldiers died in the First World War, so if the viewer follows the link between the two installations, the unease produced by Nicolai's artwork will increase.

17 The majority of freestanding artworks in the House of European History appear in its very first section "The Myth of Europa” as a representation of the idea and myth of Europe/Europa, i.e. in a very symbolic way. Artists try to capture the essence of Europe through art in multifaceted ways, leaving considerable room for interpreting the artwork on its own. 
garding aesthetic and ethical judgments on a cognitive, emotional, imaginative, or ethical level, is left up to each visitor. ${ }^{18}$

Between February 8 and April 10, 2018, the MHM displayed another work of art in the open space in the wedge, between the sections "Technology and the Military" and "Protection and Destruction": a bronze statue entitled Chor der Überlebenden (Choir of Survivors) by Dresden artist Helmut Heinze, who experienced the bombing of Dresden as a 13-year-old. The actual statue was donated to Coventry Cathedral and unveiled as part of the celebrations surrounding the fiftieth anniversary of the cathedral's rebuilding in 2012. Seven column-like figures stretched to the sky as a single group, like a choir of witnesses, expressing de-

18 Artwork has a strong symbolic, but also thought-provoking, value when it establishes constellations and associations in an exhibition between objects, interior, and exterior spaces. The MHM's 2018 special exhibition Gender and Violence: War is for Men - Peace is for Women? was accompanied by the exhibition Targeted Interventions that displayed seven art objects (six exterior works located around two sides of the building, on the building, and in the interior). On the one hand, the majority of this artwork served a symbolic function and none of it explicitly expressed anything about a specific historical period. They all were meant to challenge the visitor's perception of war and violence in an anthropological sense. On the other hand, upon closer inspection, the visitor could find many resonances with the museum's architecture, interior design, and artifacts from the permanent exhibition. At least four artworks referred to bombs and rockets, some blandly provocative like Morten Traavik's Honest John, a short range rocket capable of carrying nuclear warheads covered by condoms, while others were more dynamic, such as Birgit Dieker's Crazy Daisy, a rocket made out of mutilated female mannequin bodies. The museum's text panel explicitly related Dieker's artwork to the history of the V2 and to the habit of American Second World War pilots of decorating their planes with pin-up girls. But the visitor could find constellations to the formation section in the thematic tour, the mutilated bodies from the "War and Suffering" section, or the displayed corpses after the air attacks on Dresden in the "1918-1945" chronological and "Dresden View" sections (see chapter 8). Similarly, the shape of eight lipstick colored rockets or grenades in Sylvie Fleurie's First Spaceship on Venus in the wedge in the "Protection and Destruction" section even created a direct "viewing axis' with the 'bomb hail' installation in the permanent exhibition. The extent to which the visitor felt inspired to draw conclusions from this remains open. Lastly, the Guerilla Girls created a large poster The Estrogen Bomb on the side façade of the museum building: "pink bomb heads towards Earth for the Museum of Military History of the Bundeswehr." The text on the billboardlike artwork requested a world without homophobia, inequality, etc. Visitors could think of Davenport's The Coyote, since this time the museum was targeted with a different bomb. However, they could have also linked the artwork to the game of skill, Nuclear Bombs on Japan, displayed in the "War and Play" section, or to the many installations referring to bombs. Must bombs destroy society or could they change it? If a bomb hit the MHM, would it have any impact on the rest of the world? Visitors who wanted to engage with artwork could therefore challenge their own perceptions. 
struction and hope simultaneously. ${ }^{19}$ The visitor could clearly emotionally connect to the bodily gestures seen in the statue and support the message of reconciliation. Furthermore, the relationship between Coventry and Dresden, which have been official partner cities since 1959, seemed to have surpassed any violence caused by the war. Nevertheless, even more than Iché's Guernica sculpture in the House of European History, a narrative framework tamed the symbolic gesture of the artwork. The exhibition presented a singular interpretation: the Air War is in the past. Instead of analyzing its multifaceted relations to the present, including the continuance of violence, the museum encompassed the Air War's significance in one symbolic gesture. Of course, one could argue that the MHM's overall set-up, including the exhibition of vom Bruch's nearby Capriccio, complicated such a reading. However, Heinze's bronze sculpture was presented as an artwork with an aura of its own - prior to Walter Benjamin's shift, in the age of mechanical reproducibility, to constant simulations of aura (2008 [1935]). There were no connections through which the visitor could easily associate this artwork with other parts of the exhibition or the building's architecture. This had the effect of intensifying the stated symbolism of the artwork and discouraging alternate interpretations. Although it was located in the Libeskind wedge, it could just as easily have been placed anywhere else within the museum. Placed inside the wedge, it had the effect of simplifying or contradicting the staged, broken, and complex gaze from the top of the wedge's platform. In Heinze's artwork, the sky is unambiguously open. ${ }^{20}$

If one reflects on art in history museums, it is very noticeable that, with the exception of the Bastogne War Museum, none of the museums uses fiction (in literature or film) as a documentary source. Fiction is used - particularly in the Bundeswehr Military History Museum - to express the function of different memory media and to represent war after the fact, but not to support the simulation of historical reality. Even the four fictitious characters in the Bastogne War Museum ${ }^{21}$ do not create a fictional world, since they establish the factually illustrative claim of documenting the potentially real consciousness and perspectives of an American soldier, a German soldier, and Belgian civilians. They are created to document possible historical experiences. Their constructed nature stemming from numerous eyewitness accounts underlines this referential function. There-

19 Surprisingly, the text explaining the artwork was only in German. This neither fit with the MHM's general bilingual presentation style nor the message of the artwork expressing reconciliation between Dresden and Coventry.

20 Another form of artwork in the MHM that functions more symbolically can be seen in educational stations.

21 See chapter 4.3. 
fore, the visitor most likely never feels that these characters are part of a fictional story; they are a medium to express collective perceptions of history. Consequently, they do not violate the pact of truthfulness (Doležel 2010, 36) between museum and visitor. A historical museum that uses a fictional representation to enhance its simulation of history - whether of its own creation, or whether it stages a fictional scene from a film or literary text - has yet to be created. This would most likely require an experiential style, which would allow the visitor to empathize with fictitious characters. However, fiction could be used in a style that employs a higher degree of distantiation if the visitor was provided with the opportunity to choose between different roles in fictional scenarios. Such a tool would be more likely employed didactically, similar to the hypothetical scenarios - "What to do?" - found in the New Orleans WWII Museum. Nonetheless, fiction and possible creative demands on the visitor could add to the imaginative possibilities of understanding history and its limitations and choices of interpretation.

Fiction in film and prose does not seem to work in representing war history. Despite this, the Imperial War Museum North (IWMN), in addition to its visual artwork, uses poetry by 'writer-in-residence' Mario Petrucci as an artistic intervention. Petrucci comments in particular on objects that are personified in poems and speak to the visitor with their own fictionalized voices. Originally, this collection of poems about personified objects included a poem from the point of view of a T-34/85 tank. ${ }^{22}$ When it was on display, the museum's description highlighted the object's use in the Second World War by briefly mentioning that T-34s were in active service until the 1990s. The poem brought the artifact's background and destructive power to life, noting how boys, women, and old men produced it "deep in Russian forest" (5). Then the poem expressed a warning from the point of view of the personified tank: "For Germans I was / the can opener from Hell." (16-17). The poem ended by relating to the active duty of the tank "not so very long ago" with the line "My motto? You're dust" (20).

22 The tank - still on display in August 2013 - was replaced by a British Second World War infantry support tank, the Matilda II, as seen on a visit in May 2018. Consequently, Petrucci's poem disappeared without a replacement. Generally, the IWMN does not seem to have a continuous program for their "Reactions: Artist Interventions at the IWMN.” There was no new artwork displayed in the permanent exhibition between 2013 and 2018. However, the museum continues to display three poems by Petrucci: a reflective poem on the meaning(s) of friend and fiend; a poem from the perspective of a First World War artillery field gun; and a poem about the AV-8a Harrier combat aircraft. It also exhibits a poem by Simon Armitage about the feelings surrounding 9/11 (see also Bagnall and Rowland 2010, 59-64, for the "playful discombobulation" and creation of aesthetic contemplation through artwork, and the installation of the Harrier jet in the context of Libeskind's architecture in the IWMN in particular). 
The visitor was invited to consider the meaning of certain lines beyond their literal interpretation. How did the poem portray the destructive power of the tank? Was this power acceptable since the tank was used against the Germans? How and in which conflicts was the tank used more recently? The visitor could combine the appearance of the artifact with the poem, which created numerous affective, ethical, and cognitive allusions. Petrucci's poem - as staged in the museum - opened up possibilities for further reflection without being limited by a pragmatic museum narrative.

Even though the AV-8a Harrier was not flying in the Second World War, but rather in the 1970s and 1980s, Petrucci's Harrier poem challenges visitors to imagine themselves in a city being attacked from the air by using the point of view of the plane. This creates many allusions to the Second World War and the Blitz, as represented elsewhere in the IWMN. The plane threatens that it "can [...] see you in the City" (6-7) and that "I'll remove you from your teacup / and not spill it" $(8-9) .{ }^{23}$ The visitor is forced into an emotional dialogue with the object through the poem. Whether the poem, in the safe atmosphere of the museum, creates fear, laughter, or cognitive insights to the threats from the air aimed at civilians remains open. It certainly forces visitors who come across it to think and react for themselves and engage further with the display.

Artwork and poetry (i.e. mainly non-narrative media) - if staged in a dialogue with the contents of exhibitions, museum spaces, and exhibition's representational strategies - allows museums to engage the visitor in reflexive situations. It is perfectly suited to trigger debate or agonistic memory, in which the visitor is drawn into structural networking to understand abstract concepts such as violence and historical structures. The visitor can learn about the complexity of simulating the past. Visitors - if they are willing to engage with art can be drawn out of the comfort zone of easily digestible historical information or straightforward narrative to reflect upon the general consequences of warfare. Historical context can feed autonomous works of art; however, they more often also imply more general messages about suffering and violence as well as the human impact of war. In particular, museums that are reluctant to use artwork integrate historical works of art as expressions of suffering and trauma, such as

23 The Harrier and the poem also form a unit of reflection with Gerry Judah's sculpture The Crusader (2010), which hangs on the wall to the right of the exhibition's entrance. It is a network of war-damaged buildings in the shape of a plane, so that the viewer immediately connects it to the nearby 'real' Harrier artifact. The artist is quoted as saying that his sculpture "explores the violence of conflict against a perceived righteousness of purpose. The beauty of the sculpture contrasts with the darkness of the subject matter.” The visitor must decide how to address these contrasts. 
experiences in concentration camps or the rapes of Asian women forced to serve as sex slaves for Japanese soldiers. If the meaning of the artwork and its contextual setting in the museum is not pre-determined, museums can supplement historical representation with a more abstract reflective potential. This can draw visitors into situations of war and violence without implying cheap empathy as an alleged copy of historical reality. The constructive nature of art, poetry, and even if it is under-used - fiction, creates friction with the understanding of history. This means that it is perfectly suited to supplement the cognitive understanding of the past by triggering the visitors' imagination, which allows them to develop reflective perceptions and meaning-making skills. Museums - as a medium that creates spaces that are filled by visitors' perceptions and decisions - are ideally suited both to integrate art and history in order to widen the emotional, ethical, cognitive, and aesthetic insights of their visitors and to develop experientiality. ${ }^{24}$

24 Sharon Macdonald takes a considerably more critical and cautious view to the use of conceptual art as part of exhibiting difficult heritage and perpetration, by example of an artwork installation on the Nazi Party Rallying Grounds (2008, 110 - 115). Although there are limitations to the use of unguided or ambiguous art in war museums when exhibiting violence and perpetration, its meta-representational function of evoking critical thinking is undoubtedly significant. 